\title{
The Connection Between Home Support and Academic Achievement Amongst Undergraduate Students
}

\author{
Dr. Oz Guterman
}

Western Galilee College, Israel

\begin{abstract}
:
Academic education is a key factor in socio-economic mobility and constitutes an "entrance ticket" to many occupations and fields. Therefore, understanding the factors that underlie student success in various fields is essential in helping students to succeed.

The present study focused on the relationship between the type and level of support received by undergraduate students from their families and the connection of this support to their academic success. The research indicates that in some cases the support does not promote students' success and in some cases even harms their chances of success. A number of key explanations are presented for this interesting and unexpected result.
\end{abstract}

Keywords: academic support, academic achievement, undergraduate students 